\title{
Penerapan Line Balancing untuk Meningkatkan Proses Perakitan Control Panel di Line Service Part pada PT. Kawai Indonesia Plant 3
}

\author{
Diki Aris Styawan ${ }^{1 *}$, Wahyudin ${ }^{2}$, Hamdani $^{3}$ \\ ${ }^{1,2,3}$ Program Studi Teknik Industri, Fakultas Teknik, Universitas Singaperbangsa Karawang \\ *Koresponden email: dikiariss@gmail.com
}

Diterima: 1 Oktober 2021

Disetujui: 2 November 2021

\begin{abstract}
The development of the industrial world is getting tighter, making each company must be able to overcome productivity to meet consumer demand. In increasing productivity, of course, you must make the production process efficient. One thing that can be done is to make line balancing. The purpose of this study is to identify and propose a track balance to make the production process more efficient. The data used in this research is in the form of the initial conditions of the work station and the type of work. The method used to identify the optimal trajectory balance is the Ranked Position Weight (RPW). From the results of data processing, it is known that the initial conditions of work stations on the control panel assembly are 5 stations and 16 types of work. From the results of the calculation of cycle time and the number of stations, the optimal number of stations is reduced to 3 work stations. After calculating using the Ranked Position Weight method, it is known that the 16 types of work can be grouped into 3 work stations. Then the balance delay is obtained after reducing the work station, which is $5.48 \%$ from the initial condition of $43.29 \%$. Then the line efficiency after station reduction is $94.52 \%$ from the initial condition of $56.71 \%$. Then the smoothing index after improvement was 0.983 from the initial condition of 6.128. From the results of the three indicators, it can be seen that the reduction of the station gives better results.
\end{abstract}

Keywords: line balancing, production, cycle time, work station, RPW

\begin{abstract}
Abstrak
Perkembangan dunia industri yang semakin ketat, membuat tiap perusahaan harus mampu mengatasi produktivitas untuk memenuhi permintaan konsumen. Dalam meningkatkan produktivitas tentu harus membuat proses produksi menjadi efisien. Salah satu hal yang dapat dilakukan adalah dengan membuat keseimbangan lintasan (line balancing). Tujuan penelitian ini adalah untuk mengidentifikasi dan mengusulkan keseimbangan lintasan agar proses produksi lebih efisien. Data yang digunakan pada penelitian ini adalah berupa kondisi awal stasiun kerja dan jenis pekerjaannya. Metode yang digunakan untuk mengidentifikasi keseimbangan lintasan optimal adalah dengan Ranked Position Weight (RPW). Dari hasil pengolahan data diketahui kondisi awal stasiun kerja pada perakitan control panel sebanyak 5 stasiun dan 16 jenis pekerjaan. Dari hasil pada perhitungan waktu siklus dan jumlah stasiun didapatkan pengurangan jumlah stasiun optimal yaitu menjadi 3 stasiun kerja. Setelah dilakukan perhitungan dengan menggunakan metode Ranked Position Weight diketahui dari 16 jenis pekerjaan tersebut dapat dikelompokkan ke dalam 3 stasiun kerja. Kemudian didapatkan balance delay setelah pengurangan stasiun kerja yaitu 5,48\% dari kondisi awal 43,29\%. Lalu line efficiency setelah pengurangan stasiun sebesar 94,52\% dari kondisi awal 56,71\%. Kemudian smoothing Index setelah perbaikan sebesar 0,983 dari kondisi awal 6,128. Dari hasil ketiga indikator tersebut dapat diketahui bahwa pengurangan stasiun tersebut memberi hasil yang lebih baik.
\end{abstract}

Kata Kunci: keseimbangan lintasan, produksi, waktu siklus, stasiun kerja, RPW

\section{Pendahuluan}

Seiring dengan perkembangan dunia industri dari hari ke hari yang saat ini semakin meningkat, perusahaan harus memenuhi permintaan dengan meningkatkan produktivitas produksinya [1]. Efisiensi produksi dan produktivitas yang tinggi adalah hal yang harus diciptakan oleh perusahaan sebagai respon dari persaingan tersebut. Dalam menciptakan produksi yang optimum, perusahaan harus menyesuaikan kapasitas produksi dengan kebutuhan dari konsumen [2]. Karena itu perusahaan sangat perlu untuk mengadakan efektivitas, efisiensi, dan produktivitas agar dapat bersaing di era seperti sekarang. Persaingan yang semakin tinggi ini, produktivitas bukan hanya menjadi kebutuhan melainkan tuntutan. Banyak hal 
yang mempengaruhi produktivitas salah satunya lini produksi [3]. Salah satu cara dalam meningkatkan kapasitas produksi adalah dengan pengoptimalan sumber daya untuk menghasilkan produk yang maksimal dengan tetap memperhatikan aspek kualitas dan kuantitas produk [4].

Dalam berkontribusi pada hal tersebut dapat dilakukan dengan melakukan perencanaan sistem produksi yang tepat yaitu keseimbangan lintasan produksi [5]. Perencanaan ini sangat berpengaruh dalam proporsi dan manajemen pekerjaan yang harus dilakukan [6]. Keseimbangan lintasan berhubungan dengan cara suatu pekerjaan dalam stasiun kerja dapat berjalan dengan optimal [7]. Masalah pada keseimbangan lintasan ini adalah mengenai cara agar suatu pekerjaan dapat selesai dalam waktu yang sama juga dengan beban kerja yang sama juga [8]. Keseimbangan lintasan ialah suatu penyesuaian pekerjaan yang terdapat pada stasiun kerja yang dimiliki dimana saling berkaitan satu sama lain [9]. Dengan demikian, dalam upaya menciptakan produksi yang lancar maka perlu dilakukan identifikasi untuk penyeimbangan lintasan [10]. Lintasan atau lini produksi dapat dikatakan seimbang apabila waktu siklus yang dimiliki stasiun kerja dapat merata [11]. Fungsinya adalah untuk minimasi stasiun kerja dan waktu menganggur pada stasiun kerja secara keseluruhan [12].

PT. Kawai Indonesia Plant 3 merupakan perusahaan yang bergerak dalam bidang industri alat musik khususnya piano, baik piano akustik maupun piano digital. Dalam proses produksinya terdapat satu lintasan produksi untuk assembly atau perakitan komponen control panel. Lintasan produksi tersebut memiliki lima stasiun kerja dengan jumlah pekerja sebanyak lima orang. Masalah yang sering di hadapi oleh lintasan produksi control panel adalah terlambatnya waktu siklus aktual dengan waktu siklus yang telah ditetapkan oleh perusahaan. Hal tersebut diakibatkan karena pekerjaan antar stasiun kerja yang tidak merata dan tata letak stasiun kerja yang masih kurang efisien sehingga waktu operasi antar stasiun kerja menjadi jauh berbeda dan banyak terjadi waktu menganggur (idle time).

Adapun beberapa penelitian yang digunakan sebagai acuan diantaranya penelitian yang dilakukan [13] digunakan analisis line balancing dalam upaya meningkatkan output pada produksi sepatu bola. Penelitian yang dilakukan [14] penerapan line balancing digunakan untuk mengefisiensikan pada proses line face lathe. Penelitian yang dilakukan [15], line balancing digunakan untuk meningkatkan kapasitas produksi di perusahaan otomotif. Penelitian yang dilakukan [16], analisis keseimbangan lintasan diterapkan untuk mengurangi waktu tunggu pada proses leak test valve. Penelitian yang dilakukan oleh [17] digunakan analisis line balancing untuk menciptakan efisiensi kerja yang maksimal di setiap stasiun kerja pada perusahaan garmen. Tujuan penelitian ini adalah untuk mengidentifikasi dan mengusulkan keseimbangan lintasan agar proses produksi lebih efisien.

\section{Metode Penelitian}

Dilakukan studi pendahuluan dalam tahap awal penelitian yaitu dengan studi lapangan untuk mengetahui kondisi yang menjadi objek penelitian. Sedangkan studi pendahuluan dilakukan untuk mendalami metode pada literatur atau penelitian terdahulu agar mendapatkan hasil penelitian yang baik. Data didapatkan dengan Teknik observasi, wawancara, dan pengukuran waktu. Data yang digunakan pada penelitian yaitu berupa data primer dan sekunder. Data primer seperti kondisi lintasan awal, waktu siklus pada proses kerja, serta jumlah pekerjaan dan stasiun kerja saat ini. Sedangkan data sekunder seperti spesifikasi produk dan profil perusahaan. Dalam menganalisis lintasan produksi, pada penelitian ini menggunakan metode Rank Positional Weight (RPW). Langkah analisis data dimulai dengan melakukan identifikasi lintasan saat ini kemudian dilakukan pengukuran waktu siklus, lalu balance delay, line efficiency, dan smoothing index. Selanjutnya akan diidentifikasi Kembali menggunakan RPW untuk mendapat lintasan lebih baik dan digambarkan lintasan usulan yang telah diidentifikasi. Langkah terakhir adalah penarikan kesimpulan terhadap hasil yang didapatkan. Adapun tahapan penelitian tergambar pada Gambar 1.

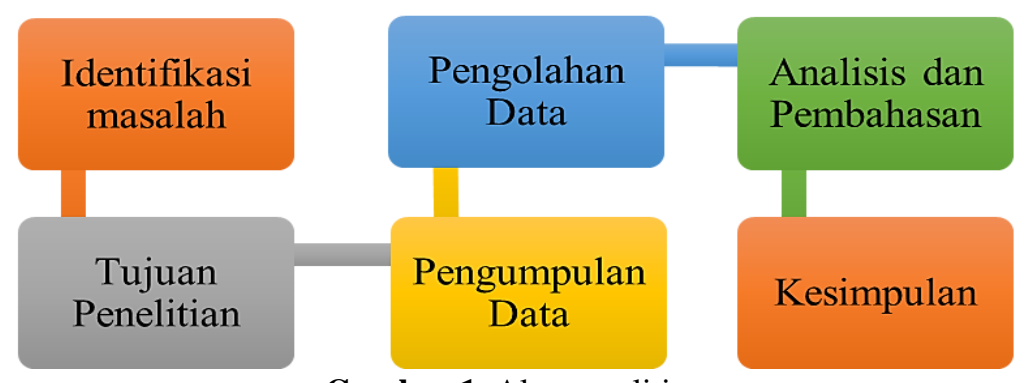

Gambar 1. Alur penelitian

Sumber: Pengolahan data penulis (2021) 


\section{Hasil dan Pembahasan}

Dalam upaya menyeimbangkan lintasan produksi pada PT. Kawai Indonesia Plant 3 khususnya pada perakitan control panel memerlukan beberapa tahapan yaitu sebagai berikut:

\section{a. Identifikasi Kondisi Awal Stasiun Kerja}

Tahap yang pertama adalah dengan mengidentifikasi kondisi eksisting stasiun kerja pada perakitan control panel. Berikut merupakan gambaran awal kondisi stasiun kerja di line service part, diantaranya:

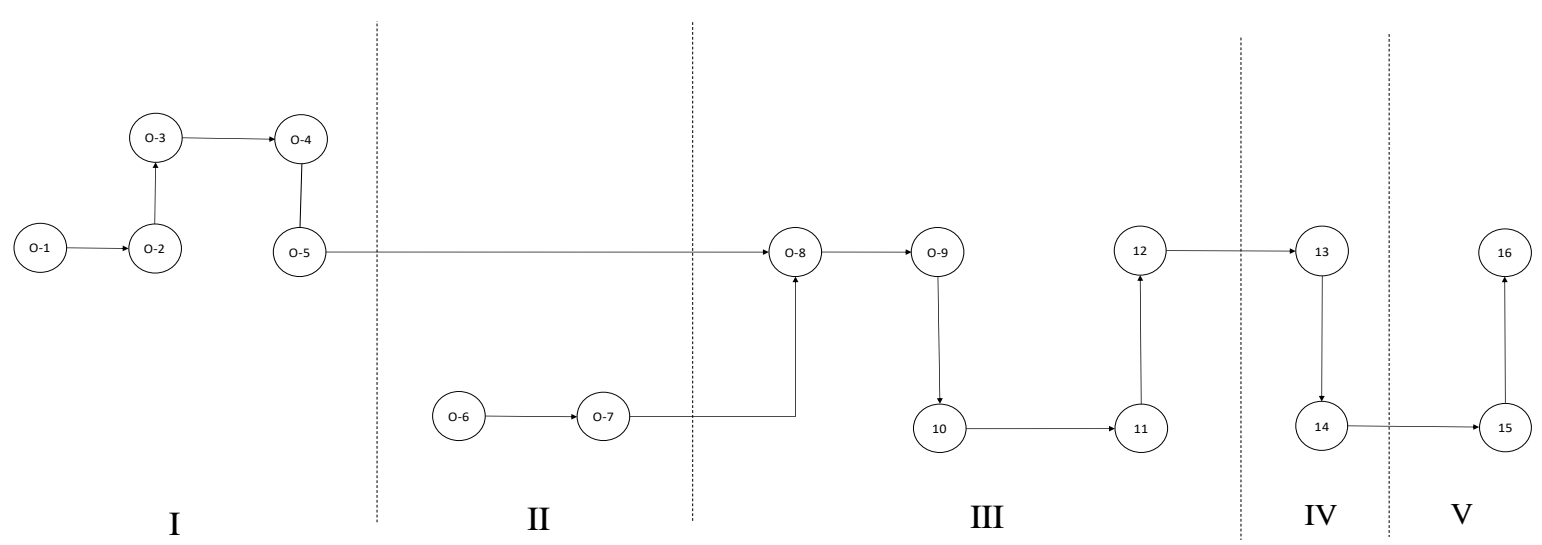

Gambar 2. Kondisi awal stasiun kerja

Sumber: Pengolahan data peneliti (2021)

Pada Gambar 1 dapat dilihat kondisi awal stasiun kerja di line service part dengan jumlah 5 buah stasiun kerja, 16 elemen kerja dan 5 orang operator dengan masing-masing 1 operator tiap stasiun kerja. Setiap elemen kerja memiliki jenis pekerjaan yang berbeda-beda. Penjelasan mengenai jenis pekerjaan pada tiap elemen kerja dapat dilihat pada Tabel 1.

Tabel 1. Keterangan tiap elemen kerja

\begin{tabular}{cl}
\hline Elemen Kerja & \multicolumn{1}{c}{ Pekerjaan } \\
\hline O-1 & Transport dari Pallet menuju Stasiun Kerja \\
O-2 & Unpacking Control Panel \\
O-3 & Install Key Top to Control Panel \\
O-4 & Instal LCD Cover \& Cloth \\
O-5 & Throw Control Panel to Box \\
O-6 & Assy Power Cable \\
O-7 & Assy LCD with Cable \\
O-8 & Assy PCB to Control Panel \\
O-9 & Assy LCD to Control Panel \\
O-10 & Assy Cable to Control Panel \\
O-11 & Assy Power Button \\
O-12 & QC Control Panel \\
O-13 & Wiring Cable \\
O-14 & Visual Check \& Cleaning \\
O-15 & Packing 1 \\
O-16 & Packing 2 \\
& Sumber: Pengolahan data peneliti (2021)
\end{tabular}

\section{b. Menghitung Waktu Operasi Tiap Elemen Kerja}

Tiap elemen kerja yang ada di line service part memiliki tingkat kesulitan dan jenis pekerjaan yang berbeda, begitu pula dengan waktu operasi tiap elemen pasti akan berbeda pula. Rincian mengenai waktu operasi masing-masing elemen kerja dapat dilihat pada Tabel 2.

Tabel 2. Waktu operasi stasiun kerja

\begin{tabular}{cccc}
\hline Stasiun Kerja & Kode Operasi & Waktu Operasi (Menit) & Idle Time (Menit) \\
\hline & 1 & 0.15 & \\
I & 2 & 0.30 & 1.7 \\
& 3 & 3.85 & \\
\hline
\end{tabular}




\begin{tabular}{|c|c|c|c|}
\hline \multicolumn{2}{|c|}{ Cycle Time } & \multicolumn{2}{|l|}{5.45} \\
\hline Stasiun Kerja & Kode Operasi & Waktu Operasi (Menit) & Idle Time (Menit) \\
\hline \multirow{2}{*}{ II } & 6 & 1.15 & \multirow{2}{*}{3.8} \\
\hline & 7 & 2.20 & \\
\hline \multicolumn{2}{|c|}{ Cycle Time } & 3.35 & \\
\hline \multirow{5}{*}{ III } & 8 & 3.10 & \multirow{5}{*}{0} \\
\hline & 9 & 1.15 & \\
\hline & 10 & 1.45 & \\
\hline & 11 & 0.30 & \\
\hline & 12 & 1.15 & \\
\hline \multicolumn{2}{|c|}{ Cycle Time } & 7.15 & \\
\hline \multirow{2}{*}{ IV } & 13 & 3.45 & \multirow{2}{*}{1.85} \\
\hline & 14 & 1.85 & \\
\hline \multicolumn{2}{|c|}{ Cycle Time } & 5.30 & \\
\hline $\mathrm{V}$ & 15 & 1.75 & \multirow{2}{*}{4.1} \\
\hline v & 16 & 1.30 & \\
\hline \multicolumn{2}{|c|}{ Cycle Time } & 3.05 & \\
\hline \multicolumn{2}{|c|}{ Total } & 24.3 & 9.75 \\
\hline
\end{tabular}

Sumber: Pengolahan data peneliti (2021)

c. Menghitung Cycle Time dan Jumlah Stasiun Kerja Optimal

1) Cycle Time

Cycle time pada penelitian ini menggunakan data yang telah diberikan oleh perusahaan, dimana perusahaan menargetkan dapat melakukan assembly 7 buah komponen control panel dalam 1 jam. Sehingga nilai cycle time yaitu 8,57.

2) Jumlah Stasiun Kerja

Untuk menghitung jumlah stasiun kerja yang optimal dapat dilakukan dengan rumus;

Jumlah Stasiun Kerja $=\frac{\text { Total Operation Time }}{\text { Cycle Time }}$

Jumlah Stasiun Kerja $=\frac{24,30}{8,57}=2,835 \approx 3$ Stasiun Kerja

d. Menghitung Balance Delay, Line Efficiency, dan Smoothness Index Awal

Setelah melakukan pengukuran dan analisa data, berikut merupakan tahap awal perhitungan dan pembahasan, diantaranya:

1) Balance Delay

$D=\left|n . c-\frac{\sum_{i=1}^{n} t i}{n . c}\right| \times 100 \%$

$D=\left|5.8,15-\frac{24,3}{5.8,15}\right| x 100 \%$

$D=43,29 \%$

2) Line Efficiency

$\eta=100 \%-D$

$\eta=100 \%-43,29 \%$

$\eta=56,71 \%$

3) Smoothnes Index

$$
\begin{aligned}
& S I=\sqrt{\sum_{i=1}^{K}(S T \max -S T i)^{2}} \\
& S I=\sqrt{(1,7)^{2}+(3,8)^{2}+(1,85)^{2}+(4,1)^{2}} \\
& \text { SI }=6,128
\end{aligned}
$$

\section{e. Membuat Precedence Diagram}

Pembuatan precedence diagaram digunakan untuk menggambarkan hubungan antar elemen kerja seperti pada Gambar 3. 


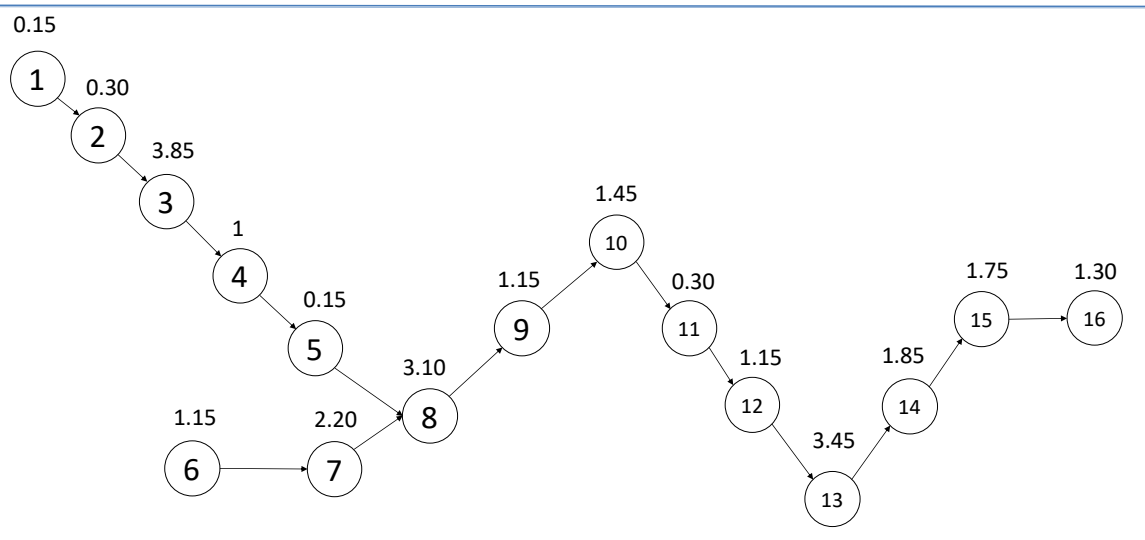

Gambar 3. Hasil Precedence Diagram

Sumber: Pengolahan data peneliti (2021)

\section{f. Perhitungan Dengan Metode Ranking Position Weight (RPW)}

Perhitungan keseimbangan lini kerja dengan metode RPW dimulai dengan menjumlahkan point setiap elemen kerja, penjumlahan point dilakukan berdasarkan hubungan antar elemen yang mengacu pada precedence diagram. Berikut merupakan perhitungan RPW seperti pada Tabel 3.

Tabel 3. Hasil perhitungan RPW

\begin{tabular}{llc}
\hline $\begin{array}{l}\text { Elemen } \\
\text { Kerja }\end{array}$ & \multicolumn{1}{c}{ Penjumlahan RPW } & $\begin{array}{c}\text { Total } \\
\text { RPW }\end{array}$ \\
\hline RPW-1 & $0.15+0.30+3.85+1+0.15+3.10+1.15+1.45+0.30+1.15+3.45+1.85+1.75+1.30$ & 20.95 \\
RPW-2 & $0.30+3.85+1+0.15+3.10+1.15+1.45+0.30+1.15+3.45+1.85+1.75+1.30$ & 20.8 \\
RPW-3 & $3.85+1+0.15+3.10+1.15+1.45+0.30+1.15+3.45+1.85+1.75+1.30$ & 20.5 \\
RPW-4 & $1+0.15+3.10+1.15+1.45+0.30+1.15+3.45+1.85+1.75+1.30$ & 16.65 \\
RPW-5 & $0.15+3.10+1.15+1.45+0.30+1.15+3.45+1.85+1.75+1.30$ & 15.65 \\
RPW-6 & $1.15+2.20+3.10+1.15+1.45+0.30+1.15+3.45+1.85+1.75+1.30$ & 18.85 \\
RPW-7 & $2.20+3.10+1.15+1.45+0.30+1.15+3.45+1.85+1.75+1.30$ & 17.7 \\
RPW-8 & $3.10+1.15+1.45+0.30+1.15+3.45+1.85+1.75+1.30$ & 15.5 \\
RPW-9 & $1.15+1.45+0.30+1.15+3.45+1.85+1.75+1.30$ & 12.4 \\
RPW-10 & $1.45+0.30+1.15+3.45+1.85+1.75+1.30$ & 11.25 \\
RPW-11 & $0.30+1.15+3.45+1.85+1.75+1.30$ & 9.8 \\
RPW-12 & $1.15+3.45+1.85+1.75+1.30$ & 9.5 \\
RPW-13 & $3.45+1.85+1.75+1.30$ & 8.35 \\
RPW-14 & $1.85+1.75+1.30$ & 4.9 \\
RPW-15 & $1.75+1.30$ & 3.05 \\
RPW-16 & 1.30 & 1.30 \\
\hline
\end{tabular}

Sumber: Pengolahan data peneliti (2021)

Setelah melakukan penjumlahan poin, tahap selanjutnya adalah mengurutkan atau menilai total poin RPW dari yang paling besar hingga yang paling kecil dan didapat hasil pada Tabel 4.

Tabel 4. Hasil RPW setelah diurutkan

\begin{tabular}{llc}
\hline $\begin{array}{l}\text { Elemen } \\
\text { Kerja }\end{array}$ & \multicolumn{1}{c}{ Penjumlahan RPW } & $\begin{array}{c}\text { Total } \\
\text { RPW }\end{array}$ \\
\hline RPW-1 & $0.15+0.30+3.85+1+0.15+3.10+1.15+1.45+0.30+1.15+3.45+1.85+1.75+1.30$ & 20.95 \\
RPW-2 & $0.30+3.85+1+0.15+3.10+1.15+1.45+0.30+1.15+3.45+1.85+1.75+1.30$ & 20.8 \\
RPW-3 & $3.85+1+0.15+3.10+1.15+1.45+0.30+1.15+3.45+1.85+1.75+1.30$ & 20.5 \\
RPW-4 & $1.15+2.20+3.10+1.15+1.45+0.30+1.15+3.45+1.85+1.75+1.30$ & 18.85 \\
RPW-5 & $2.20+3.10+1.15+1.45+0.30+1.15+3.45+1.85+1.75+1.30$ & 17.7 \\
RPW-6 & $1+0.15+3.10+1.15+1.45+0.30+1.15+3.45+1.85+1.75+1.30$ & 16.65 \\
RPW-7 & $0.15+3.10+1.15+1.45+0.30+1.15+3.45+1.85+1.75+1.30$ & 15.65 \\
RPW-8 & $3.10+1.15+1.45+0.30+1.15+3.45+1.85+1.75+1.30$ & 15.5 \\
RPW-9 & $1.15+1.45+0.30+1.15+3.45+1.85+1.75+1.30$ & 12.4 \\
RPW-10 & $1.45+0.30+1.15+3.45+1.85+1.75+1.30$ & 11.25 \\
RPW-11 & $0.30+1.15+3.45+1.85+1.75+1.30$ & 9.8 \\
RPW-12 & $1.15+3.45+1.85+1.75+1.30$ & 9.5 \\
RPW-13 & $3.45+1.85+1.75+1.30$ & 8.35 \\
\hline
\end{tabular}




\begin{tabular}{llc}
\hline $\begin{array}{l}\text { Elemen } \\
\text { Kerja }\end{array}$ & \multirow{2}{*}{ Penjumlahan RPW } & Total \\
RPW-14 & $1.85+1.75+1.30$ & 4.9 \\
RPW-15 & $1.75+1.30$ & 3.05 \\
RPW-16 & 1.30 & 1.30 \\
\hline
\end{tabular}

Sumber: Pengolahan data peneliti (2021)

Setelah mengurutkan rangking point RPW, tahap selanjutnya adalah membagi elemen kerja ke dalam stasiun kerja sesuai dengan jumlah stasiun kerja yang optimal. Waktu operasi saat Pembagian elemen kerja ke dalam stasiun kerja tidak boleh melebihi waktu siklus. Berikut pembagian seperti pada Tabel 5.

Tabel 5. Hasil pembagian elemen kerja

\begin{tabular}{|c|c|c|c|c|c|}
\hline Stasiun Kerja & Elemen Kerja & Waktu Operasi & Waktu Stasiun & Waktu Siklus & Idle Time \\
\hline \multirow[t]{5}{*}{ 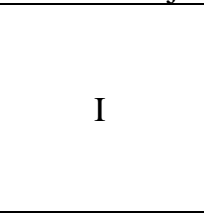 } & 1 & 0.15 & \multirow{5}{*}{7.65} & 8.57 & \multirow{5}{*}{0.92} \\
\hline & 2 & 0.30 & & 8.57 & \\
\hline & 3 & 3.85 & & 8.57 & \\
\hline & 6 & 1.15 & & 8.57 & \\
\hline & 7 & 2.20 & & 8.57 & \\
\hline \multirow{7}{*}{ II } & 4 & 1 & \multirow{7}{*}{8.3} & 8.57 & \multirow{7}{*}{0.27} \\
\hline & 5 & 0.15 & & 8.57 & \\
\hline & 8 & 3.10 & & 8.57 & \\
\hline & 9 & 1.15 & & 8.57 & \\
\hline & 10 & 1.45 & & 8.57 & \\
\hline & 11 & 0.30 & & 8.57 & \\
\hline & 12 & 1.15 & & 8.57 & \\
\hline III & 13 & 3,45 & 8,35 & 8,57 & \\
\hline Stasiun Kerja & Elemen Kerja & Waktu Operasi & Waktu Stasiun & Waktu Siklus & Idle Time \\
\hline \multirow{3}{*}{ III } & 14 & 1.85 & \multirow{3}{*}{8.35} & 8.57 & \\
\hline & 15 & 1.75 & & 8.57 & \\
\hline & 16 & 1.30 & & 8.57 & \\
\hline
\end{tabular}

Sumber: Pengolahan data peneliti (2021)

g. Menghitung Balance Delay, Line Effeciency, dan Smoothness Index Awal

1) Balance Delay

$$
\begin{aligned}
& D=\left|n . c-\frac{\sum_{i=1}^{n} t i}{n \cdot c}\right| \times 100 \% \\
& D=\left|3 \cdot 8,57-\frac{24,3}{3 \cdot 7,57}\right| \times 100 \% \\
& D=5,48 \%
\end{aligned}
$$

2) Line Efficiency

$$
\begin{aligned}
& \eta=100 \%-D \\
& \eta=100 \%-5,48 \% \\
& \eta=94,52
\end{aligned}
$$

3) Smoothnes Index

$$
\begin{aligned}
& S I=\sqrt{\sum_{i=1}^{K}(\text { STmax }-S T i)^{2}} \\
& S I=(0,92)^{2}+(0,27)^{2}+(0,22)^{2} \\
& S I=0,983
\end{aligned}
$$

Setelah melakukan penyeimbangan lini kerja atau line balancing dengan metode Rank Position Weight, terjadi pengurangan jumlah stasiun kerja yang awalnya berjumlah 5 stasiun kerja menjadi 3 stasiun kerja. Hasil tersebut dapat dilihat pada Gambar 4. 


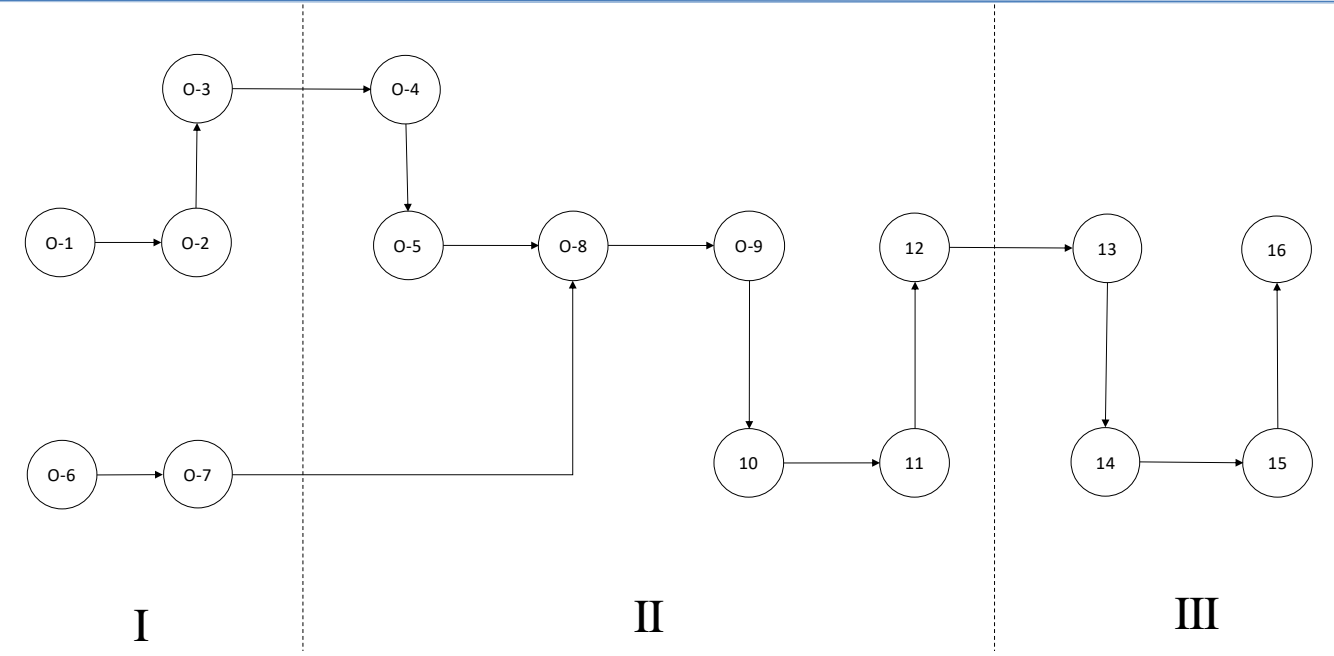

Gambar 4. Kondisi Akhir Stasiun Kerja

Sumber: Pengolahan data penulis (2021)

\section{Kesimpulan}

Berdasarkan hasil yang didapatkan, diketahui bahwa proses perakitan control panel memiliki lima stasiun kerja dengan 16 jenis pekerjaan. Dari hasil pada perhitungan waktu siklus dan jumlah stasiun didapatkan pengurangan jumlah stasiun optimal yaitu menjadi 3 stasiun kerja. Setelah dilakukan perhitungan dengan menggunakan metode RPW diketahui dari 16 jenis pekerjaan tersebut dapat dikelompokkan ke dalam 3 stasiun kerja. Kemudian didapatkan balance delay setelah pengurangan stasiun kerja yaitu 5,48\% dari kondisi awal 43,29\%. Lalu line efficiency setelah pengurangan stasiun sebesar $94,52 \%$ dari kondisi awal $56,71 \%$. Kemudian smoothing Index setelah perbaikan sebesar 0,983 dari kondisi awal 6,128. Dari hasil ketiga indikator tersebut dapat diketahui bahwa pengurangan stasiun tersebut memberi hasil yang lebih baik.

\section{Daftar Pustaka}

[1] H. Saptono and A. Wardani, "Analisis assembly line balancing produk head lamp Type K59A dengan pendekatan metode helgeson-birnie studi kasus PT . Indonesia Stanley electric," J. Rekayasa Mesin, vol. 12, no. 1, pp. 7-14, 2017.

[2] Casban dan L. H. Kusumah, "Analisis keseimbangan lintasan untuk menciptakan proses produksi pump packaging systems yang efisien di PT. Bumi Cahaya Unggul," in Seminar Nasional Sains dan Teknologi 2016, 2016, no. 1, pp. 1-12.

[3] G. S. N. Arifiana and I. W. Suletra, "Analisis line balancing dengan rpw pada departemen sewing assembly line style F1625W404 di PT. Pan Brothers, Boyolali," in Seminar dan Konferensi Nasional IDEC 2017, 2017, no. 1, pp. 8-9.

[4] D. Siregar dan A. Yasid, "Analisis peningkatan kapasitas produksi pada proses pembuatan frame motor klx dengan metode line balancing di PT . KMI," J. MATRIK, vol. 19, no. 1, pp. 37-48, 2018.

[5] M. I. P. Karmawan, F. Pulansari, dan D. S. Donoriyanto, "Analisis line balancing menggunakan metode largest candidate rule, killbridge and western method, dan ranked positional weights methods di PT. XYZ," Juminten, vol. 01, no. 01, pp. 43-54, 2020.

[6] S. Arbi, I. Ibrahim, dan I. Habibie, "Implementasi konsep line balancing dengan menggunakan metode RPW pada produksi sanjal jepit di PT Pratika Nugraha Jaya," Bull. Appl. Ind. Eng. Theory, vol. 2, no. 2, pp. 119-123, 2021.

[7] A. T. Panudju, B. S. Panulisan, dan E. Fajriati, "Analisis penerapan konsep penyeimbangan lini (line balancing) dengan metode ranked position weight (RPW) pada sistem produksi penyamakan kulit di PT. Tong Hong Tannery Indonesia Serang Banten,” J. Integr. Sist. Ind., vol. 5, no. 2, 2018.

[8] J. Pradesi, N. A. Yaqin, dan R. Yahya, "Meningkatkan efisiensi lintasan kerja menggunakan metode RPW dan Killbridge western di PT. Sango Ceramic Indonesia," J. Sains Indones., vol. 2, no. 1, pp. 20-27, 2021.

[9] M. R. Basalamah, H. N. Azizah, U. Kholifah, dan H. C. Suroso, "Implementasi line balancing pada proses produksi baju taqwa di UD. Sofi Garment," in seminar nasional teknologi industri berkelanjutan i (senastitan i), 2021, pp. 307-312. 
[10] A. Tajikusumawan dan W. Wahyani, "Implementasi line balancing dalam industri penyamakan kulit sapi (studi kasus pada UD. Restu Kulit, Magetan)," Cyber Tech, vol. 14, no. 01, pp. 52-64, 2019.

[11] D. Aryadi, "Penerapan keseimbangan lini produksi daging boneless di PT. Dagsap Endura Eatore menggunakan pendekatan pemodelan sistem," IEJST (Industrial Eng. J. Univ. Sarjanawiyata Tamansiswa), vol. 4, no. 2, pp. 87-96, 2020.

[12] D. P. Setyawan, F. Pulansari, dan K. R. Hayati, "Analisa line balancing menggunakan metode moodie young dan ranked positional weight di CV. XYZ," Juminten, vol. 02, no. 01, pp. 84-95, 2021.

[13] M. Afifudin, "Penerapan line balancing menggunakan metode ranked position weight (RPW) untuk meningkatkan output produksi pada home industri pembuatan sepatu bola," J. Ind. Eng. Manag., vol. 4, no. 1, pp. 38-46, 2019.

[14] M. Mughni dan R. P. Sari, "Penerapan metode line balancing untuk efisiensi produksi pada bagian line face lathe (Studi Kasus PT. XYZ ),” J. Teknovasi, vol. 8, no. 2, pp. 1-14, 2021.

[15] H. H. Azwir, K. C. Aryanto, dan H. Oemar, "Analisis line balancing pada line x cc machining department di perusahaan otomotif untuk peningkatan kapasitas produksi," J. IPTEK, vol. 24, no. 1, pp. 27-36, 2020.

[16] E. Manurung, Z. Arifin, dan A. Merjani, "Penerapan line balancing untuk mengurangi waktu menunggu pada proses leak test valve (Studi kasus di PT.Tomoe Valve Batam)," Profisiensi, vol. 8, no. 2, pp. 129-133, 2020.

[17] A. F. Dasanti, D. F. Jakdan, dan T. Santoso, "Penerapan konsep line balancing untuk mencapai efisiensi kerja yang optimal pada setiap stasiun kerja di PT Garment Jakarta," Bull. Appl. Ind. Eng. Theory, vol. 1, no. 2, pp. 2-7, 2020. 